\title{
Probiotics and necrotizing enterocolitis
}

\author{
Paul Fleming ${ }^{1,2}$, Nigel J Hall ${ }^{3,4} \&$ Simon Eaton $^{4}$ \\ ${ }^{1}$ Homerton University Hospital, \\ ${ }^{2}$ Barts and the London School of Medicine and Dentistry, \\ ${ }^{3}$ Faculty of Medicine, University of Southampton, \\ ${ }^{4}$ UCL Institute of Child Health and Great Ormond Street Hospital for Children, London
}

Corresponding author:

Simon Eaton, $\mathrm{PhD}$

Department of Paediatric Surgery, UCL Institute of Child Health, 30 Guilford Street, London, WC1N 1EH

UK

Telephone: +44 (0)20 79052158

Fax: +44 (0)20 74046181

Email: s.eaton@ucl.ac.uk

Keywords: necrotizing enterocolitis, probiotics, prevention, intestinal microbiota, premature infants, randomized controlled trials 


\begin{abstract}
Probiotics for the prevention of necrotizing enterocolitis have attracted a huge interest. Combined data from heterogeneous randomised controlled trials suggest that probiotics may decrease the incidence of NEC. However, the individual studies use a variety of probiotic products, and the group at greatest risk of NEC, i.e. those with a birth weight of less than $1000 \mathrm{~g}$, are relatively under-represented in these trials so we do not have adequate evidence of either efficacy or safety to recommend universal prophylactic administration of probiotics to premature infants. These problems have polarized neonatologists, with some taking the view that it is unethical not to universally administer probiotics to premature infants, whereas others regard the meta-analyses as flawed and that there is insufficient evidence to recommend routine probiotic administration. Another problem is that the mechanism by which probiotics might act is not clear, although some experimental evidence is starting to accumulate. This may allow development of surrogate endpoints of effectiveness, refinement of probiotic regimes, or even development of pharmacological agents that may act through the same mechanism. Hence, although routine probiotic administration is controversial, studies of probiotic effects may ultimately lead us to effective means to prevent this devastating disease.
\end{abstract}


Although necrotizing enterocolitis (NEC) is one of the most common life-threatening surgical diseases affecting neonates, we still do not completely understand the pathogenesis, or how to prevent or treat the disease [1]. The mortality for surgical NEC remains high, at around $30 \%[2,3]$, and although therapies such as stem cells provide some promise [4], unless there is a major novel development, it is unlikely that improvements in the surgical or medical treatment of unstable infants with major gut necrosis will significantly reduce this mortality [5]. Survivors of acute NEC may have long-term morbidities related both to gut necrosis (e.g. short bowel syndrome [6]) and systemic sequelae (e.g. adverse neurodevelopmental outcome [7]). Given the morbidity and mortality and the lack of specific treatment, there is an urgent need for development of preventative strategies. A huge amount of interest and hope bordering on evangelism has been invested in the routine administration of probiotics to prevent or eradicate this disease. Neonatologists are quite polarized on the issue of probiotics to prevent NEC: proponents of probiotics regard the fact that probiotics are not routinely given to premature neonates as unethical, detractors regard the meta-analyses combining different probiotic strains as deeply scientifically flawed. The American Pediatric Surgical Association Outcomes and Clinical Trials Committee considered the level of evidence for routine probiotic supplementation and concluded that 'Substantial data support routine supplementation of enteral intake with probiotics in premature infants to reduce the incidence of severe NEC (Grade A/B). No formal recommendations regarding the formulation, timing or duration of supplementation could be determined, but at least one probiotic formulation initiated in the first week of life and continued for at least two weeks appears appropriate.' [8]. However, it was also noted in this review that 'No conclusions regarding probiotic use in ELBW (< 1000 grams) infants could be extrapolated from the studies due to limited data.'

The aims of this review article are to discuss the rationale for the administration of probiotics to prevent NEC, the scientific basis for their action, and briefly discuss the current evidence for effectiveness.

\section{Pathogenesis of NEC}

Although the pathogenesis of NEC is incompletely understood, there are several established risk factors, including prematurity, altered intestinal blood flow / oxygen 
delivery, formula (as opposed to human breast milk) feeding, immature immune responses and a bacterial component. While the precise role of bacterial agents in the development of NEC is unclear, several factors implicate their involvement. Occasionally NEC is observed to occur in clusters, in which a higher than expected number of cases are observed in one centre [9]. Identical organisms are grown from babies within these clusters and the initiation of infection control measures has been shown to control such outbreaks [10]. However, different organisms are grown from separate outbreaks so it cannot be claimed that a single organism is involved in development of NEC. Bacterial involvement in the pathogenesis of NEC is also implicated by association; endotoxaemia $[11,12]$ and positive blood cultures are common in infants with NEC and the gastrointestinal pneumatosis found in NEC contains 30\% hydrogen [13], a gas produced solely by bacterial metabolism. Recent work implicating bacteria in the pathogenesis of NEC has also come from studies suggesting that NEC can be predicted before onset of clinical symptoms by analysis of fecal volatile organic compounds, which are likely to originate from intestinal microbiota $[14,15]$. However, colonization of the neonatal intestine is a complex process, and before considering the impact of probiotic administration on the incidence of NEC, it is important to consider the microbiome of the premature infant.

\section{The Infant Microbiome}

The adult human harbours a rich and diverse microbial community. It is estimated that microbes in the human body collectively outnumber human cells by a factor of 10 to 1 and that they encode for 100-fold more unique genes than our own genome [16]. The vast majority of these microbes are found in the gastrointestinal tract which is estimated to contain more than 1000 prevalent bacterial species [17]. Intestinal bacteria and humans usually establish a mutual relationship with each other. This relationship is encapsulated by the word commensal which originates from the Latin cum mensa or 'sharing a table'[18]. In return for providing a stable environment that is rich in energy sources derived from ingested food, intestinal microbiota provide important functions such as nutrient acquisition and energy regulation by breaking down otherwise indigestible food [19]. They also play a number of protective roles which include: 
development of the intestinal epithelium; limitation of pathogen colonisation by competing for adherence to epithelial surfaces; production of antimicrobial compounds; and regulation of intestinal immune responses [20]. Our natural microbial community evolves with us and plays a significant role in both health and disease. Changes in our microbiome have been implicated in a range of pathological conditions from obesity through to inflammatory bowel disease [21-23].

The original belief (first hypothesised at the turn of the $20^{\text {th }}$ century) that humans develop within a sterile uterine environment [24] has more recently been challenged by increasing evidence that the infants' initial inoculum can be provided by maternal transmission before birth [25]. Further evidence refuting the belief that an infant's intestine is sterile at birth comes from the recent identification of numerous microorganisms in meconium [26]. The early establishment of an infants' microbiota is very unstable [27] and is influenced by a number of factors [28]. The most important of these factors likely include the mode of delivery [29] and feeding type during the initial post-partum period [30]. Vaginally delivered babies acquire their mothers' vaginal flora at birth (by contrast, babies delivered by Caesarean section are colonised with bacterial communities resembling the skin) [29,31]. Following initial inoculation, culture based studies suggest that aerobic species such as Enterobacteriaceae, staphylococci and streptococci become established early colonisers during the first 2-3 days and their presence creates an anaerobic environment which facilitates the growth of species such as Clostridia, Bacteroides and Bifidobacteria [32]. Breastmilk is an additional rich source of microbes [33]. By the end of the first week after birth, Bifidobacteria dominate the flora of breast fed infants with formula fed infants harbouring a more heterogeneous intestinal microbial community [34]. During infancy, a unique balance is formed by gastrointestinal microbes and host tolerance and diet, all of which influence the acquisition and eventual stability of the intestinal microflora [35].

In preterm babies, the normal succession of bacterial colonisers may be interrupted by a variety of factors. Infants are usually nursed away from their mothers in the sterile and often hostile environment of the intensive care unit. Birth by caesarean section, broad 
spectrum antibiotic administration, delayed initiation of feeds and placement of invasive catheters can interrupt the process of normal colonisation and result in a more restricted enteric microbiota with delayed colonisation by Bifidobacteria [36,37]. In contrast to term infants, the gastrointestinal tract of preterm babies lacks microbial diversity and frequently becomes colonised with limited numbers of bacterial flora. It is often dominated by potentially pathogenic species including: Enterobacteria, E. coli, Bacteroides, Eenterococci, Streptococci, Staphylococci and Klebsiella [38,39]. As a commensal microbiome is self-perpetuating [40], so, similarly, is an abnormal microbiome, in the sense that a failure to establish a normal spectrum of commensals within the gut predisposes to further pathogenic colonisation. Abnormal pathogenic intestinal microbiomes are characteristically less diverse than normal gut flora [41], and consequently do not induce the competitive environment which limits the influx of extrinsic pathogens. Similarly, the aforementioned homeostatic behaviour of commensal organisms (i.e. inflammatory dampening, induction of self-sustaining nutrition) is absent, leading to instability of the microbiome.

It has been suggested that the risk of developing NEC, (similar to other inflammatory bowel conditions like Chron's disease) is increased when the balance between pathogenic and commensal bacteria shifts in favour of the former resulting in an abnormal microbiome. This is facilitated through impairment of the natural barriers to bacterial translocation, creation of a pro-inflammatory milieu, and perpetuating an unstable microbiome, unfavourable to re-colonisation with commensals. Although no specific bacterial species have been associated with the development of NEC, studies have shown that the presence of some abnormal intestinal flora is associated with a greater risk of NEC [42]. Rather than a single causative agent, it is more likely that the composition or structure of the preterm intestinal bacterial community plays a role in disease development [43]. High throughput sequencing of bacterial flora from preterm infants shows that babies who develop NEC cluster separately from controls [44]. Furthermore, a close temporal relationship has been demonstrated between abnormal microbial colonisation patterns and NEC, with 'blooms' of pathogenic $\gamma$-proteobacteria seen to precede the onset of clinical NEC by several days [45]. With the advent of modern 
pyrosequencing methods for microbiome analysis, we can expect more studies on the role of microbiota in the development of NEC. However, such data are very complex, and analysis of these data in a very heterogeneous disease like NEC is extremely challenging. Nevertheless, recent studies have suggested a loss in microbial diversity to occur immediately before NEC onset [46,47], with a consequent predominance of Escherichia spp. [46] or strict anaerobes [47].

\section{Probiotics for the prevention of NEC}

In 1907, Nobel laureate Elie Metchnikoff proposed that yoghurt (containing probiotics) prolonged life [48]. The World Health Organisation defines probiotics as live organisms (bacteria and yeast) that, when ingested in sufficient amounts, have a beneficial effect on the overall health of the host [49]. Probiotics are derived from fermented foods, from beneficial commensals or from the environment and have been shown to act through diverse mechanisms from alteration of the commensal microbiota to modification of gut barrier function and intestinal immune responses [50]. Given their propensity for abnormal colonisation patterns, using probiotics to manipulate and potentially normalise the intestinal flora of preterm babies is an attractive therapeutic potential. This intervention might have particular relevance to diseases such as NEC where, changes in the gut microbial community preceding the onset of symptoms, has previously been demonstrated $[45,44]$.

Proof of concept studies showing the ability of probiotic species to successfully colonise the preterm intestine began to emerge in the early 1990s [51]. Further evidence that probiotics might benefit preterm infants was reported by Kitajima and colleagues in 1997 who, in addition to demonstrating successful recovery of this probiotic from stool also reported that its administration was associated with a reduction in apnoea and vomiting [52]. In 1999, Hoyos and colleagues reported the outcome of a cohort study, in which,

probiotic administration was associated with a reduction in the incidence of necrotizing enterocolitis [53]. Between 2003 and 2006, several randomised studies reported a reduction in the incidence of NEC among preterm babies recruited to probiotic trials (and 
receiving the probiotic intervention) though not all these studies were designed to evaluate NEC as a primary outcome [54-59]. The first meta-analysis combining these results was published in 2007 and concluded that probiotics might reduce the risk of NEC in preterm babies born less 33 weeks gestation [60]. A further meta-analysis published by the Cochrane Collaboration in 2009 concluded that probiotics reduced the incidence of NEC in babies >1000g birth-weight [61].

Despite these findings, enthusiasm for implementing the routine use of probiotics was hampered by numerous concerns. These concerns centred around the heterogeneity of probiotics used in individual studies, lack of data relating to optimum dosing and timing of intervention, short and long term safety of probiotics and perhaps most importantly, the lack of evidence for benefit among infants who might be deemed most at risk of developing NEC [62-64] and in particular those <1000g. Additional concerns were raised about the quality of trials included in various meta-analyses. In 2012, Mihatsch and colleagues systematically analysed the level of evidence of published randomised controlled trials on probiotics in preterm babies in order to evaluate whether a statistically confirmatory basis could be provided to recommend routine probiotic use in very low birth weight babies (VLBW) to prevent NEC, sepsis, death and feeding tolerance. This study applied robust and validated methods to assess the quality of individual trials used in prior meta-analyses and reported that only 2 of 15 trials provided Level of Evidence (LoB) $1 \mathrm{~b}$ neither of which supported the use of probiotics in preterm babies [65]. In the absence of confirmatory studies, many researchers agreed that a number of these concerns could only be addressed by further large randomised controlled trials.

In 2013, researchers from the University of Melbourne were the first to report the finding of the largest published neonatal probiotics trial to date [66]. This well designed study addressed many of the previous concerns raised in relation to smaller trials and as such, the importance of this study cannot be understated. Most importantly, the authors reported a statistically significant reduction in NEC (Bell's stage 2 or 3) among infants born at $<32$ weeks gestation and randomised to receive a probiotic intervention containing three probiotic species. Infants who benefited most were those born at $\geq 28$ 
week's gestation and $\geq 1000 \mathrm{~g}$ birthweight. However, NEC development was a secondary outcome to this trial, the primary outcome of which was late onset sepsis.

The results of further large trials recruiting a more appropriate target patient group are eagerly awaited. One such study (The UK based PIPs trial) was designed with a primary outcome of sepsis, NEC or death, and recruited 1315 infants <31 weeks completed gestation [67] in England. This trial may provide further insight into the role of probiotics in the more immature preterm population. .

The most recent updated Cochrane review on the use of probiotics in preterm babies includes more than 20 studies involving $>5000$ babies and includes data from the Australian ProPrems study. The reviewers conclude that enteral supplementation of probiotics prevents severe NEC and all-cause mortality in preterm babies [68]. But the evidence of benefit for babies born $<1000 \mathrm{~g}$ birthweight (those babies deemed most at risk for NEC) remains less clear.

\section{Safety of probiotics in preterm infants}

Concerns about short and long term safety of using currently available probiotic interventions remain. Although some commentators have suggested that probiotic interventions should be considered separate to drug trials (because they are readily available as health supplements) [69] others have cautioned about the potential risks associated with their use [70]. Standard culture techniques do not reliably detect probiotic bacteria so sepsis due to probiotic micro-organisms may be under-reported. Hence, crucially, it cannot be concluded that probiotics are either effective or safe in the highest risk population. The case for addressing safety concerns is particularly important given the recent identification of Rhizopus oryzae in unopened probiotic containers and the death of a preterm baby from invasive fungal disease (http://www.fda.gov/Food/RecallsOutbreaksEmergencies/Outbreaks/ucm423830.htm).

The product implicated in this case is the same as that used in two previous randomised trials $[56,66]$ (one of which was the large Australian ProPREMS study) though neither of these groups reported any serious events during the course of their trials. Adverse events 
associated with using bacteria to manipulate the flora of premature babies have previously been described. During the 1960s numerous papers reported the efficacy of an apparent avirulent strain of Staphylococcus aureus 502A in aborting outbreaks of staphylococcal disease through the phenomenon of bacterial interference [71]. But the reported benefits were short-lived when the increasing use of this intervention was associated with the development of pustules in a high proportion of treated infants attributable to a mutated form of the bacteria [72].

\section{Mechanistic basic science studies on probiotics}

One aspect that contributes to unease regarding clinical uptake of probiotics, but might ultimately help to define a product, is the lack of mechanistic understanding of how probiotics might prevent NEC. The literature on potential mechanisms of probiotic action is mainly from experimental models. Although there are various experimental models of NEC, and several have been used to examine the effects of probiotics in NEC, none seem to completely recapitulate the human condition [73]. Data from a clinically relevant model (spontaneous NEC in premature pigs) hint as to why routine introduction of probiotics is less than straightforward. In 2 separate studies, by the same group, divergent results were obtained $[74,75]$. In one study, probiotics decreased severity of NEC lesions (but did not affect incidence) [74], whereas in the other, probiotics significantly increased the incidence and severity of NEC [75]. These differing results illustrate in a microcosm the multifactorial and unpredictable nature of NEC and why we might not always expect consistent effects from probiotic administration to premature infants with very different microbiota.

A general assumption is that probiotics may reduce the incidence of NEC by altering the gut microbiome in favour of a more 'friendly' population of bacterial species which in turn reduces the risk of NEC. However, alteration of gut flora is only one potential mechanism by which probiotics might prevent NEC. Other mechanisms include effects on the gut immune system and via TLR-related signaling [76,77] and effects on mucosal integrity and intestinal permeability [78,79]. However, whether these are primary or secondary effects is extremely difficult to dissect, as the microbiome, immune system, 
mucosal integrity and gut barrier function are all mutually interdependent. Mechanistic studies in human infants are clearly difficult, but the group of Walker and Nanthakumar [80] has established protocols using immature human intestine that provides mechanistic insights. In one of these, intestinal tissue from therapeutic terminations of pregnancy is implanted in immune-deficient mice, the xenografts allowed to mature for 20 or 30 weeks to model immature intestine (i.e. susceptible to NEC) or mature intestine respectively, and then challenged with inflammatory stimuli. In addition, enterocytes were isolated from resected ileum of an infant with NEC. Using these model systems, probiotic bacteria decreased inflammation, but, intriguingly, these effects could be reproduced by a small soluble factor produced by the probiotic bacteria. These data are supported by further studies which suggest that soluble factors secreted by Bifidobacterium infantis and Lactobacillus acidophilus are effective in preventing enterocyte damage [81,82]. If this soluble factor(s) were to be identified, it might be possible to use this factor pharmacologically for NEC prophylaxis, which may be easier to get accepted into routine clinical practice than a pot pourri of probiotics. Intriguingly, it has recently been suggested that the bacterial DNA alone of the probiotic strain Lactobacillus rhamnosus HNOO1 is sufficient to protect against NEC in a mouse model via activation of the TLR9 pathway [83]. A greater mechanistic understanding of the actions of probiotics may also allow development of surrogate endpoints of effectiveness, and refinement of probiotic regimes, as well as development of pharmacological agents.

\section{Prebiotics and synbiotics}

Other terms which have been used in connection with prevention of NEC, although neither are well researched, are 'prebiotics' and 'synbiotics'. Prebiotics are essentially dietary fibre, i.e. complex carbohydrates that are not readily digestible, but that are digestible by probiotic micro-organisms. Synbiotics are products that contain both prebiotics and probiotics, where the prebiotic acts synergistically as a substrate for the administered probiotic. Thus either prebiotics alone or synbiotics could also have beneficial effects on the microbiome of the premature infant. The only RCT addressing whether prebiotics or synbiotics can prevent NEC in premature infants showed that the rate of NEC was lower in pro- and syn- biotic supplemented infants than in prebiotic 
supplemented or control infants. There was no evidence to support a benefit of synbiotic over probiotic supplementation [84].

\section{Other concepts}

Whilst the focus of scientific attention to date has been on the primary prevention of NEC by the use of probiotics, there are other related clinical scenarios in which there could be rationale for probiotic administration. One such scenario is following an episode of NEC since there is the potential for the use of probiotics after an episode of NEC to reduce the incidence of recurrent disease. Typical treatment for NEC includes 5-10 days 'nil-bymouth' with administration of broad spectrum antibiotics, after which enteral feeds are cautiously re-introduced. A proportion of these infants go on to experience further episodes of NEC. Whilst it is not clear how many infants with early NEC experience recurrent episodes, approximately $10 \%$ of infants with advanced NEC have recurrence [18]. This period of refeeding following a period of antibiotic 'cleansing' may provide an opportunity to use probiotics to redress the balance of the intestinal microbiome in favour of 'friendly' bacteria, and possibly decrease the incidence of recurrent NEC. To our knowledge there have been no studies to date that have examined this issue; such initial studies would necessarily have a primary aim of safety.

\section{Conclusions}

There is no doubt that the use of probiotics offers an exciting potential to reduce important complications of prematurity including NEC but no studies to date have been conducted that can causally link clinical improvements to probiotic induced changes in the microbiota. We know that NEC is a complex disease, and that the intestinal microbiome is extremely intricate. Maybe the message from the sometimes confusing meta-analyses and RCTs is that we are being a little naïve in expecting a single probiotic to work like a drug, when it is in fact quite a complicated intervention. It is possible that providing a balanced mixture is beneficial - a parallel can be made with the ability of fecal microbiota transplantation to prevent recurrent $C$. difficile infection. Ongoing 
randomised studies underpinned by studies of mechanistic action and robust long term follow-up are needed to address the many important unanswered questions that remain, that include (i) which probiotic strains to use?; (ii) when to administer?; (iii) who will benefit; and (iv) who might we harm.

\section{Acknowledgements}

SE gratefully acknowledges support from Great Ormond Street Hospital Children's Charity, PF gratefully acknowledges the support Barts and the London Charity.

\section{References}

1. Hall NJ, Eaton S, Pierro A (2013) Necrotizing enterocolitis: Prevention, treatment, and outcome. Journal of Pediatric Surgery 48 (12):2359-2367

2. Fitzgibbons SC, Ching Y, Yu D, Carpenter J, Kenny M, Weldon C, Lillehei C, Valim C, Horbar JD, Jaksic T (2009) Mortality of necrotizing enterocolitis expressed by birth weight categories. J Pediatr Surg 44 (6):1072-1075

3. Thyoka M, De Coppi P, Eaton S, Khoo K, Hall NJ, Curry J, Kiely E, Drake D, Cross K, Pierro A (2012) Advanced necrotizing enterocolitis part 1: mortality. EurJ PediatrSurg $22(1): 8-12$

4. Zani A, Cananzi M, Fascetti-Leon F, Lauriti G, Smith VV, Bollini S, Ghionzoli M, D'Arrigo A, Pozzobon M, Piccoli M, Hicks A, Wells J, Siow B, Sebire NJ, Bishop C, Leon A, Atala A, Lythgoe MF, Pierro A, Eaton S, De Coppi P (2014) Amniotic fluid stem cells improve survival and enhance repair of damaged intestine in necrotising enterocolitis via a COX-2 dependent mechanism. Gut 63 (2):300-309

5. Caplan M, Frost B (2011) Myth: Necrotizing enterocolitis: Probiotics will end the disease, and surgical intervention improves the outcome. Seminars in Fetal \& Neonatal Medicine 16 (5):264-268

6. Kelleher J, Mallick H, Soltau TD, Harmon CM, Dimmitt RA (2013) Mortality and intestinal failure in surgical necrotizing enterocolitis. J Pediatr Surg 48 (3):568-572

7. Rees CM, Pierro A, Eaton S (2007) Neurodevelopmental outcomes of neonates with medically and surgically treated necrotizing enterocolitis. ArchDisChild Fetal Neonatal Ed 92 (3):F193-F198

8. Downard CD, Renaud E, St Peter SD, Abdullah F, Islam S, Saito JM, Blakely ML, Huang EY, Arca MJ, Cassidy L, Aspelund G (2012) Treatment of necrotizing enterocolitis: an American Pediatric Surgical Association Outcomes and Clinical Trials Committee systematic review. Journal of Pediatric Surgery 47 (11):2111-2122

9. van Acker J, de Smet F, Muyldermans G, Bougatef A, Naessens A, Lauwers S (2001) Outbreak of necrotizing enterocolitis associated with Enterobacter sakazakii in powdered milk formula. J ClinMicrobiol 39 (1):293-297

10. Rotbart HA, Levin MJ (1983) How contagious is necrotizing enterocolitis? PediatrInfectDis 2 (5):406-413 
11. Scheifele DW (1990) Role of bacterial toxins in neonatal necrotizing enterocolitis. Journal of Pediatrics 117 (1 Pt 2):S44-S46

12. Scheifele DW, Olsen EM, Pendray MR (1985) Endotoxinemia and thrombocytopenia during neonatal necrotizing enterocolitis. AmJClinPathol 83 (2):227-229

13. Cheu HW, Brown DR, Rowe MI (1989) Breath hydrogen excretion as a screening test for the early diagnosis of necrotizing enterocolitis. Am J DisChild 143 (2):156-159

14. de Meij TGJ, van der Schee MPC, Berkhout DJC, van de Velde ME, Jansen AE, Kramer BW, van Weissenbruch MM, van Kaam AH, Andriessen P, van Goudoever JB, Niemarkt HJ, de Boer NKH Early Detection of Necrotizing Enterocolitis by Fecal Volatile Organic Compounds Analysis. The Journal of Pediatrics. doi:http://dx.doi.org/10.1016/j.jpeds.2015.05.044

15. Garner CE, Ewer AK, Elasouad K, Power F, Greenwood R, Ratcliffe NM, Costello BD, Probert CS (2009) Analysis of Faecal Volatile Organic Compounds in Preterm Infants Who Develop Necrotising Enterocolitis: A Pilot Study. Journal of Pediatric Gastroenterology and Nutrition 49 (5):559-565

16. Ley RE, Peterson DA, Gordon JI (2006) Ecological and evolutionary forces shaping microbial diversity in the human intestine. Cell 124 (4):837-848. doi:10.1016/j.cell.2006.02.017

17. Qin J, Li R, Raes J, Arumugam M, Burgdorf KS, Manichanh C, Nielsen T, Pons N, Levenez F, Yamada T, Mende DR, Li J, Xu J, Li S, Li D, Cao J, Wang B, Liang H, Zheng H, Xie Y, Tap J, Lepage P, Bertalan M, Batto JM, Hansen T, Le Paslier D, Linneberg A, Nielsen HB, Pelletier E, Renault P, Sicheritz-Ponten T, Turner K, Zhu H, Yu C, Li S, Jian M, Zhou Y, Li Y, Zhang X, Li S, Qin N, Yang H, Wang J, Brunak S, Dore J, Guarner F, Kristiansen K, Pedersen O, Parkhill J, Weissenbach J, Meta HITC, Bork P, Ehrlich SD, Wang J (2010) A human gut microbial gene catalogue established by metagenomic sequencing. Nature 464 (7285):59-65. doi:10.1038/nature08821

18. Cerutti A, Rescigno M (2008) The biology of intestinal immunoglobulin A responses. Immunity 28 (6):740-750. doi:10.1016/j.immuni.2008.05.001

19. Macpherson AJ, Harris NL (2004) Interactions between commensal intestinal bacteria and the immune system. Nature reviews Immunology 4 (6):478-485. doi:10.1038/nri1373 20. Rakoff-Nahoum S, Paglino J, Eslami-Varzaneh F, Edberg S, Medzhitov R (2004) Recognition of commensal microflora by toll-like receptors is required for intestinal homeostasis. Cell 118 (2):229-241. doi:10.1016/j.cell.2004.07.002

21. Guinane CM, Cotter PD (2013) Role of the gut microbiota in health and chronic gastrointestinal disease: understanding a hidden metabolic organ. Therapeutic advances in gastroenterology 6 (4):295-308. doi:10.1177/1756283X13482996

22. Zhang H, DiBaise JK, Zuccolo A, Kudrna D, Braidotti M, Yu Y, Parameswaran P, Crowell MD, Wing R, Rittmann BE, Krajmalnik-Brown R (2009) Human gut microbiota in obesity and after gastric bypass. Proc Natl Acad Sci U S A 106 (7):2365-2370. doi:10.1073/pnas.0812600106

23. Frank DN, St Amand AL, Feldman RA, Boedeker EC, Harpaz N, Pace NR (2007) Molecular-phylogenetic characterization of microbial community imbalances in human inflammatory bowel diseases. Proc Natl Acad Sci U S A 104 (34):13780-13785. doi:10.1073/pnas.0706625104

24. Tissier H (1900) Recherches sur la flore Intestinale des Nourrissons. Thesis no 529, Paris., Paris, 
25. Funkhouser LJ, Bordenstein SR (2013) Mom knows best: the universality of maternal

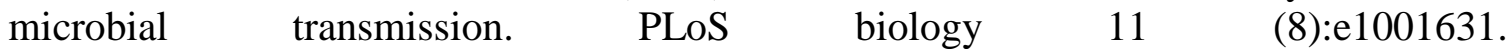
doi:10.1371/journal.pbio.1001631

26. Jimenez E, Marin ML, Martin R, Odriozola JM, Olivares M, Xaus J, Fernandez L, Rodriguez JM (2008) Is meconium from healthy newborns actually sterile? Research in microbiology 159 (3):187-193. doi:10.1016/j.resmic.2007.12.007

27. Dominguez-Bello MG, Blaser MJ, Ley RE, Knight R (2011) Development of the human gastrointestinal microbiota and insights from high-throughput sequencing. Gastroenterology 140 (6):1713-1719. doi:10.1053/j.gastro.2011.02.011

28. Penders J, Thijs C, Vink C, Stelma FF, Snijders B, Kummeling I, van den Brandt PA, Stobberingh EE (2006) Factors influencing the composition of the intestinal microbiota in early infancy. Pediatrics 118 (2):511-521. doi:10.1542/peds.2005-2824

29. Dominguez-Bello MG, Costello EK, Contreras M, Magris M, Hidalgo G, Fierer N, Knight R (2010) Delivery mode shapes the acquisition and structure of the initial microbiota across multiple body habitats in newborns. Proc Natl Acad Sci U S A 107 (26):11971-11975. doi:10.1073/pnas.1002601107

30. Gronlund MM, Gueimonde M, Laitinen K, Kociubinski G, Gronroos T, Salminen S, Isolauri E (2007) Maternal breast-milk and intestinal bifidobacteria guide the compositional development of the Bifidobacterium microbiota in infants at risk of allergic disease. Clinical and experimental allergy : journal of the British Society for Allergy and Clinical Immunology 37 (12):1764-1772. doi:10.1111/j.13652222.2007.02849.x

31. Gronlund MM, Lehtonen OP, Eerola E, Kero P (1999) Fecal microflora in healthy infants born by different methods of delivery: permanent changes in intestinal flora after cesarean delivery. J Pediatr Gastroenterol Nutr 28 (1):19-25

32. Morelli L (2008) Postnatal development of intestinal microflora as influenced by infant nutrition. J Nutr 138 (9):1791S-1795S

33. Martin R, Langa S, Reviriego C, Jiminez E, Marin ML, Xaus J, Fernandez L, Rodriguez JM (2003) Human milk is a source of lactic acid bacteria for the infant gut. J Pediatr 143 (6):754-758. doi:10.1016/j.jpeds.2003.09.028

34. Barrett E, Deshpandey AK, Ryan CA, Dempsey EM, Murphy B, O'Sullivan L, Watkins C, Ross RP, O'Toole PW, Fitzgerald GF, Stanton C (2015) The neonatal gut harbours distinct bifidobacterial strains. Arch Dis Child Fetal Neonatal Ed. doi:10.1136/archdischild-2014-306110

35. Hopkins MJ, Sharp R, Macfarlane GT (2001) Age and disease related changes in intestinal bacterial populations assessed by cell culture, 16S rRNA abundance, and community cellular fatty acid profiles. Gut 48 (2):198-205

36. Schwiertz A, Gruhl B, Lobnitz M, Michel P, Radke M, Blaut M (2003) Development of the intestinal bacterial composition in hospitalized preterm infants in comparison with breast-fed, full-term infants. Pediatr Res 54 (3):393-399. doi:10.1203/01.PDR.0000078274.74607.7A

37. Adlerberth I, Wold AE (2009) Establishment of the gut microbiota in Western infants. Acta Paediatr 98 (2):229-238. doi:10.1111/j.1651-2227.2008.01060.x

38. Westerbeek EA, van den Berg A, Lafeber HN, Knol J, Fetter WP, van Elburg RM (2006) The intestinal bacterial colonisation in preterm infants: a review of the literature. Clin Nutr 25 (3):361-368. doi:10.1016/j.clnu.2006.03.002 
39. Rouge C, Goldenberg O, Ferraris L, Berger B, Rochat F, Legrand A, Gobel UB, Vodovar M, Voyer M, Roze JC, Darmaun D, Piloquet H, Butel MJ, de La Cochetiere MF (2010) Investigation of the intestinal microbiota in preterm infants using different methods. Anaerobe 16 (4):362-370. doi:10.1016/j.anaerobe.2010.06.002

40. Sears CL (2005) A dynamic partnership: celebrating our gut flora. Anaerobe 11 (5):247-251. doi:10.1016/j.anaerobe.2005.05.001

41. Neu J, Walker WA (2011) Necrotizing enterocolitis. The New England journal of medicine 364 (3):255-264. doi:10.1056/NEJMra1005408

42. de la Cochetiere MF, Piloquet H, des Robert C, Darmaun D, Galmiche JP, Roze JC (2004) Early intestinal bacterial colonization and necrotizing enterocolitis in premature infants: the putative role of Clostridium. Pediatric research 56 (3):366-370. doi:10.1203/01.PDR.0000134251.45878.D5

43. Claud EC (2009) Neonatal Necrotizing Enterocolitis -Inflammation and Intestinal Immaturity. Anti-inflammatory \& anti-allergy agents in medicinal chemistry 8 (3):248259. doi:10.2174/187152309789152020

44. Wang Y, Hoenig JD, Malin KJ, Qamar S, Petrof EO, Sun J, Antonopoulos DA, Chang EB, Claud EC (2009) 16S rRNA gene-based analysis of fecal microbiota from preterm infants with and without necrotizing enterocolitis. The ISME journal 3 (8):944954. doi:10.1038/ismej.2009.37

45. Mai V, Young CM, Ukhanova M, Wang X, Sun Y, Casella G, Theriaque D, Li N, Sharma R, Hudak M, Neu J (2011) Fecal microbiota in premature infants prior to necrotizing enterocolitis. PLoS One 6 (6):e20647. doi:10.1371/journal.pone.0020647

46. Stewart CJ, Marrs EC, Nelson A, Lanyon C, Perry JD, Embleton ND, Cummings SP, Berrington JE (2013) Development of the preterm gut microbiome in twins at risk of $\begin{array}{llllll}\text { necrotising enterocolitis and sepsis. PLoS One } 8 \text { (8):e73465. } & \end{array}$ doi:10.1371/journal.pone.0073465

47. Brower-Sinning R, Zhong D, Good M, Firek B, Baker R, Sodhi CP, Hackam DJ, Morowitz MJ (2014) Mucosa-Associated Bacterial Diversity in Necrotizing Enterocolitis. PLoS ONE 9 (9):e105046. doi:10.1371/journal.pone.0105046

48. Metchnikoff E, Mitchell PC (1907) The prolongation of life; optimistic studies. W. Heinemann;

G.P. Putnam's Sons, London,

New York,

49. Food and Agriculture Organization of the United Nations., World Health Organization. (2006) Probiotics in food : health and nutritional properties and guidelines for evaluation. FAO food and nutrition paper,, vol 85. Food and Agriculture Organization of the United Nations : World Health Organization, Rome

50. Sanders ME, Guarner F, Guerrant R, Holt PR, Quigley EM, Sartor RB, Sherman PM, Mayer EA (2013) An update on the use and investigation of probiotics in health and disease. Gut 62 (5):787-796. doi:10.1136/gutjnl-2012-302504

51. Millar MR, Bacon C, Smith SL, Walker V, Hall MA (1993) Enteral feeding of premature infants with Lactobacillus GG. Arch Dis Child 69 (5 Spec No):483-487

52. Kitajima H, Sumida Y, Tanaka R, Yuki N, Takayama H, Fujimura M (1997) Early administration of Bifidobacterium breve to preterm infants: randomised controlled trial. Arch Dis Child Fetal Neonatal Ed 76 (2):F101-107 
53. Hoyos AB (1999) Reduced incidence of necrotizing enterocolitis associated with enteral administration of Lactobacillus acidophilus and Bifidobacterium infantis to neonates in an intensive care unit. International journal of infectious diseases : IJID : official publication of the International Society for Infectious Diseases 3 (4):197-202

54. Dani C, Biadaioli R, Bertini G, Martelli E, Rubaltelli FF (2002) Probiotics feeding in prevention of urinary tract infection, bacterial sepsis and necrotizing enterocolitis in preterm infants. A prospective double-blind study. Biology of the neonate 82 (2):103108. doi:63096

55. Costalos C, Skouteri V, Gounaris A, Sevastiadou S, Triandafilidou A, Ekonomidou C, Kontaxaki F, Petrochilou V (2003) Enteral feeding of premature infants with Saccharomyces boulardii. Early Hum Dev 74 (2):89-96

56. Bin-Nun A, Bromiker R, Wilschanski M, Kaplan M, Rudensky B, Caplan M, Hammerman C (2005) Oral probiotics prevent necrotizing enterocolitis in very low birth weight neonates. J Pediatr 147 (2):192-196. doi:10.1016/j.jpeds.2005.03.054

57. Lin HC, Su BH, Chen AC, Lin TW, Tsai CH, Yeh TF, Oh W (2005) Oral probiotics reduce the incidence and severity of necrotizing enterocolitis in very low birth weight infants. Pediatrics 115 (1):1-4. doi:10.1542/peds.2004-1463

58. Manzoni P, Mostert M, Leonessa ML, Priolo C, Farina D, Monetti C, Latino MA, Gomirato G (2006) Oral supplementation with Lactobacillus casei subspecies rhamnosus prevents enteric colonization by Candida species in preterm neonates: a randomized study. Clinical infectious diseases : an official publication of the Infectious Diseases Society of America 42 (12):1735-1742. doi:10.1086/504324

59. Mohan R, Koebnick C, Schildt J, Schmidt S, Mueller M, Possner M, Radke M, Blaut M (2006) Effects of Bifidobacterium lactis Bb12 supplementation on intestinal microbiota of preterm infants: a double-blind, placebo-controlled, randomized study. J Clin Microbiol 44 (11):4025-4031. doi:10.1128/JCM.00767-06

60. Deshpande G, Rao S, Patole S (2007) Probiotics for prevention of necrotising enterocolitis in preterm neonates with very low birthweight: a systematic review of randomised controlled trials. Lancet 369 (9573):1614-1620

61. AlFaleh K, Anabrees J, Bassler D (2010) Probiotics Reduce the Risk of Necrotizing Enterocolitis in Preterm Infants: A Meta-Analysis. Neonatology 97 (2):93-99

62. Beattie LM, Hansen R, Barclay AR (2010) Probiotics for preterm infants: confounding features warrant caution. Pediatrics 126 (3): $742-743$; author reply e743745. doi:10.1542/peds.2010-1949C

63. Neu J, Shuster J (2010) Nonadministration of routine probiotics unethical--really? Pediatrics 126 (3):e740-741; author reply e743-745. doi:10.1542/peds.2010-1949A

64. Garland SM, Jacobs SE, Tobin JM, Opie GF, Donath S, ProPrems study g (2010) A cautionary note on instituting probiotics into routine clinical care for premature infants. Pediatrics 126 (3):e741-742; author reply e743-745. doi:10.1542/peds.2010-1949B

65. Mihatsch WA, Braegger CP, Decsi T, Kolacek S, Lanzinger H, Mayer B, Moreno LA, Pohlandt F, Puntis J, Shamir R, Stadtmuller U, Szajewska H, Turck D, van Goudoever JB (2012) Critical systematic review of the level of evidence for routine use of probiotics for reduction of mortality and prevention of necrotizing enterocolitis and sepsis in preterm infants. Clinical nutrition 31 (1):6-15. doi:10.1016/j.clnu.2011.09.004 66. Jacobs SE, Tobin JM, Opie GF, Donath S, Tabrizi SN, Pirotta M, Morley CJ, Garland SM, ProPrems Study G (2013) Probiotic effects on late-onset sepsis in very preterm 
infants: a randomized controlled trial. Pediatrics 132 (6):1055-1062. doi:10.1542/peds.2013-1339

67. PIPs Study. https://www.npeu.ox.ac.uk/pips.

68. AlFaleh K, Anabrees J (2014) Probiotics for prevention of necrotizing enterocolitis in preterm infants. The Cochrane database of systematic reviews 4:CD005496. doi:10.1002/14651858.CD005496.pub4

69. Janvier A, Lantos J, Barrington K (2013) The politics of probiotics: probiotics, necrotizing enterocolitis and the ethics of neonatal research. Acta paediatrica 102 (2):116-118. doi:10.1111/apa.12083

70. Millar M, Wilks M, Fleming P, Costeloe K (2012) Should the use of probiotics in the preterm be routine? Arch Dis Child Fetal Neonatal Ed 97 (1):F70-74. doi:10.1136/adc.2009.178939

71. Shinefield HR, Ribble JC, Eichenwald HF, Boris M, Sutherland JM (1963) Bacterial interference: its effect on nursery-acquired infection with Staphylococcus aureus. V. An analysis and interpretation. Am J Dis Child 105:683-688

72. Blair EB, Tull AH (1969) Multiple infections among newborns resulting from colonization with Staphylococcus aureus 502A. Am J Clin Pathol 52 (1):42-49

73. Lu P, Sodhi CP, Jia H, Shaffiey S, Good M, Branca MF, Hackam DJ (2014) Animal models of gastrointestinal and liver diseases. Animal models of necrotizing enterocolitis: pathophysiology, translational relevance, and challenges. American Journal of Physiology - Gastrointestinal and Liver Physiology 306 (11):G917-G928

74. Siggers RH, Siggers J, Boye M, Thymann T, Molbak L, Leser T, Jensen BB, Sangild T (2008) Early administration of Probiotics alters bacterial colonization and limits dietinduced gut dysfunction and severity of necrotizing enterocolitis in preterm pigs. Journal of Nutrition 138 (8):1437-1444

75. Cilieborg MS, Thymann T, Siggers R, Boye M, Bering SB, Jensen BB, Sangild PT (2011) The Incidence of Necrotizing Enterocolitis Is Increased Following Probiotic Administration to Preterm Pigs. Journal of Nutrition 141 (2):223-230

76. Liu YY, Fatheree NY, Mangalat N, Rhoads JM (2012) Lactobacillus reuteri strains reduce incidence and severity of experimental necrotizing enterocolitis via modulation of TLR4 and NF-kappa B signaling in the intestine. American Journal of PhysiologyGastrointestinal and Liver Physiology 302 (6):G608-G617

77. Ganguli K, Collado MC, Rautava J, Lu L, Satokari R, von Ossowski I, Reunanen J, de Vos WM, Palva A, Isolauri E, Salminen S, Walker WA, Rautava S (2015) Lactobacillus rhamnosus $\mathrm{GG}$ and its $\mathrm{SpaC}$ pilus adhesin modulate inflammatory responsiveness and TLR-related gene expression in the fetal human gut. Pediatric Research 77 (4):528-535. doi:10.1038/pr.2015.5

78. Patel RM, Myers LS, Kurundkar AR, Maheshwari A, Nusrat A, Lin PW (2012) Probiotic Bacteria Induce Maturation of Intestinal Claudin 3 Expression and Barrier Function. American journal of pathology 180 (2):626-635

79. Khailova L, Patrick SKM, Arganbright KM, Halpern MD, Kinouchi T, Dvorak B (2010) Bifidobacterium bifidum reduces apoptosis in the intestinal epithelium in necrotizing enterocolitis. American Journal of Physiology-Gastrointestinal and Liver Physiology 299 (5):G1118-G1127

80. Ganguli K, Meng D, Rautava S, Lu L, Walker WA, Nanthakumar N (2013)

Probiotics prevent necrotizing enterocolitis by modulating enterocyte genes that regulate 
innate immune-mediated inflammation. American Journal of Physiology-Gastrointestinal and Liver Physiology 304 (2):G132-G141

81. Shiou S-R, Yu Y, Guo Y, He S-M, Mziray-Andrew CH, Hoenig J, Sun J, Petrof EO, Claud EC (2013) Synergistic Protection of Combined Probiotic Conditioned Media against Neonatal Necrotizing Enterocolitis-Like Intestinal Injury. PLoS ONE 8 (5):e65108. doi:10.1371/journal.pone.0065108

82. Guo S, Guo Y, Ergun A, Lu L, Walker WA, Ganguli K (2015) Secreted Metabolites of <italic>Bifidobacterium infantis $</$ italic $>$ and $<$ italic $>$ Lactobacillus acidophilus $</$ italic $>$ Protect Immature Human Enterocytes from IL-1 $\beta$-Induced Inflammation: A Transcription Profiling Analysis. PLoS ONE 10 (4):e0124549. doi:10.1371/journal.pone.0124549

83. Good M, Sodhi CP, Ozolek JA, Buck RH, Goehring KC, Thomas DL, Vikram A, Bibby K, Morowitz MJ, Firek B, Lu P, Hackam DJ (2014) Lactobacillus rhamnosus HNO01 decreases the severity of necrotizing enterocolitis in neonatal mice and preterm piglets: evidence in mice for a role of TLR9, vol 306. vol 11. doi:10.1152/ajpgi.00452.2013

84. Dilli D, Aydin B, Fettah ND, Ozyazici E, Beken S, Zenciroglu A, Okumus N, Ozyurt BM, Ipek MS, Akdag A, Turan O, Bozdag S (2015) The propre-save study: effects of probiotics and prebiotics alone or combined on necrotizing enterocolitis in very low birth weight infants. J Pediatr 166 (3):545-551 e541. doi:10.1016/j.jpeds.2014.12.004 